\title{
Como a família funciona em políticas de intervenção social?
}

\author{
How the family works in social intervention policy?
}

Patrice Schuch*

\begin{abstract}
Resumo: Neste trabalho, desejo revisitar alguns dados de campo sobre duas de minhas pesquisas - sobre a reconfiguração do campo de intervenção ao adolescente infrator no Rio Grande do Sul e sobre as políticas de abrigo no município de Porto Alegre, RS -, para refletir sobre os modos em que a família funciona em políticas de intervenção social dirigidas à infância e juventude no Brasil. Meu intuito é compreender certos processos pelos quais a família não só aparece como um domínio fundamental de formação para o indivíduo adulto, mas também é, no contexto brasileiro, inserida em políticas mais amplas de reconstrução democrática. Tais políticas priorizam a descentralização das formas de intervenção, corresponsabilização de indivíduos e comunidades na sua execução e a construção da autonomia e do protagonismo dos sujeitos, com vistas a sua transformação em "sujeitos de direitos". Neste contexto, meu objetivo é dialogar com a literatura sobre o assunto, que destaca tanto a "reprivatização das questões políticas", quanto a expansão de uma racionalidade neoliberal nas práticas de governo contemporâneas, que investem na formação de competências e capacidades individuais para o autogoverno. Como tentarei mostrar, a atenção para os processos acima descritos, embora extremamente importante, não pode ofuscar um movimento paralelo: a compreensão da complexidade de dinâmicas, valores, agentes e interesses que coproduzem tais práticas de mudança nos modos de governo de indivíduos e populações.
\end{abstract}

Palavras-chave: Família. Práticas de governo. Neoliberalismo.

Abstract: In this paper, I review field data from two of my recent studies - on the reconfiguration of the field of intervention for adolescent violators in RS and on the policies for juvenile shelters in the city of Porto Alegre, RS - to reflect on the ways in which the family functions in policies of social intervention addressing children and youth in Brazil. My purpose is to understand certain processes in which the family not only appears as a key site for the formation of adults, but, in the Brazilian context, it is also set in the broader policy of democratic reconstruction. State policies prioritize decentralized forms of intervention making individuals and communities co-responsible for the construction and implementation of autonomy and protagonism, with a view to transforming individuals into "subjects of rights". In this context, my

* Doutora em Antropologia Social pela Ufrgs, professora e pesquisadora do PPG em Antropologia Social na Ufrgs em Porto Alegre, RS, Brasil < patrice.schuch@uol.com.br>.

\begin{tabular}{|c|c|c|c|c|c|}
\hline Civitas & Porto Alegre & v. 13 & n. 2 & p. 309-325 & maio-ago. 2013 \\
\hline
\end{tabular}


aim is to dialogue with the literature on the subject, which highlights the "privatization of policy issues" as well as the expansion of a neoliberal rationality in contemporary governance practices that invest in the training of individual skills and capacities for self-government. I will argue that, despite the importance of the processes described above, the analyst should not overlook a parallel movement: the complexity of value dynamics, agents, and interests that co-produce such practices of change in the modes of governance of individuals and populations.

Keywords: Family. Governance practices. Neoliberalism.

Desde 2001 eu pesquiso os processos promovidos pela mudança legal no campo da infância e juventude, especialmente efetivados a partir da implantação do Estatuto da Criança e do Adolescente (ECA), em 1990. Foram fundamentais nesse percurso a minha pesquisa de doutorado, sobre os processos de reformulação das práticas de justiça no campo de atenção ao adolescente infrator, finalizada em 2005 (Schuch, 2009), e uma pesquisa sobre as práticas, estruturas e sentidos do abrigamento de crianças e adolescentes em Porto Alegre, que coordenei junto com Claudia Fonseca e que implicou uma equipe do Núcleo de Antropologia e Cidadania da Universidade Federal do Rio Grande do Sul (Ufrgs), finalizada um ano mais tarde, em 2006 (Schuch e Fonseca, 2009). Minhas pesquisas mais recentes, sobre o que chamo de "tecnologias da não violência" e que compreendem o estudo da implantação da justiça restaurativa e justiça comunitária, também vêm a contribuir nessa trajetória, chamando a atenção para o quanto os processos de redemocratização no Brasil devem ser pensados a partir de dois processos correlatos: de um lado, a ênfase na retórica dos direitos como instrumentos para a "modernização", desenvolvimento social e consolidação da democracia; de outro lado, a tentativa de criação de "sensibilidades modernas" e de novos tipos de pessoa, nos quais os valores da individualidade, autonomia e autorresponsabilidade são enfatizados.

Em meu entender, tais estudos mostram o quanto as transformações em curso, realizadas sob a forte ênfase no discurso dos direitos, não dizem respeito apenas a mudanças de princípios e regulamentos legais, mas também compreendem a gestão de sensibilidades sociais e subjetividades individuais como modos de governo privilegiados nesses contextos (Schuch, 2012). Pelas suas características, é possível pensar a relação entre tais modos de governo com a expansão de uma racionalidade específica, trabalhada por Nikolas Rose (1999 e 2006) como uma racionalidade neoliberal, aquela que investe na escolha como um valor fundamental de governo, assim como no desenvolvimento de 
tecnologias para instalar e apoiar o processo civilizador através do governo das capacidades, competências e desejo dos sujeitos.

Neste texto, desejo revisitar alguns dados de campo sobre duas de minhas pesquisas - sobre a reconfiguração do campo de intervenção ao adolescente infrator no Rio Grande do Sul e sobre as políticas de abrigamento no município de Porto Alegre - para refletir sobre as interfaces entre "família" e políticas de intervenção. A questão que me interesso em discutir é: como a família funciona em políticas de intervenção social?

\section{Fazendo a família "funcionar": a família como sujeito político}

Ao me interessar por essa questão, espero evidenciar um deslocamento do debate acerca dos significados ou sentidos evocados e produzidos sobre família pelos programas de intervenção social, ou mesmo das tensões particulares existentes entre sentidos, classificações e práticas em torno da família vivenciados pelos encontros singulares entre agentes implementadores de programas regulatórios e os seus agentes destinatários. Essa configuração da problemática vem recebendo bastante atenção no campo da antropologia, inclusive entre alguns de meus próprios trabalhos (cf.: Fonseca, 1995; Fonseca e Schuch, 2009; Schuch, 2009; Ribeiro, 1996; Vianna, 2002 e 2005). Também não pretendo focar no valor da família no contexto brasileiro e suas configurações concretas, a partir da problematização das relações entre tradição ou modernidade ou das transformações da sociedade brasileira e suas incidência sobre formatos de família (Duarte, 1986; Duarte, 2006; I. Ribeiro e A. Ribeiro, 1995). Meu interesse aqui é incorporar os sentidos e tensões em torno das configurações de família para fazê-la "funcionar" em outra direção, focandome no modo como ela é inserida em políticas mais amplas de reconstrução democrática.

Minha hipótese é que, olhando para certos programas de intervenção à infância e juventude, podemos compreender alguns aspectos dos processos pelos quais a "família" não só aparece como um domínio fundamental de formação da matriz para o indivíduo adulto - processo já explorado por Foucault (1977 e 1979), ao falar da "família moderna", mas também entender os modos pelos quais ela é, no contexto brasileiro, inserida em políticas mais amplas de reconstrução democrática que priorizam a descentralização das políticas, coresponsabilização de indivíduos e comunidades na sua execução e a construção da autonomia e protagonismo dos sujeitos, com vistas a sua transformação em "sujeitos de direitos".

A partir de meus dados de campo, acredito que alguns aspectos de tal inserção - que sem dúvida é bastante heterogênea e variável - podem ser 
relacionados com o já destacado papel da família para a configuração de uma "ordem pública", consciência cidadã e para a produção de uma vivência social adequada no Brasil (Duarte, 2006). No entanto, assumindo a importância de se atentar para a dimensão das variadas tecnologias de governo na produção de novos cenários culturais, gostaria de levar adiante tal relação, especificamente a partir da sugestão apontada por Debert (2006), que assinala uma espécie de "reprivatização de questões políticas" no Brasil, realizada a partir de diversas práticas e programas de instituições jurídico-policiais. Especificamente focando-se nas políticas de atenção à violência contra a mulher em São Paulo, a autora percebe um privilégio do cuidado e de preocupações com a família; nesse sentido, as práticas de intervenção "reprivatizam questões políticas" ao tomarem as famílias como seus aliados fundamentais e construir programas voltados para cidadãos construídos como malogrados ou passíveis de malogro. ${ }^{1}$ A família torna-se tanto o lugar de suspeita, quanto simultaneamente o objeto e o instrumento de intervenção: as instituições se colocam como tarefa restabelecer normas e regras tidas como essenciais ao convívio entre parentes. Como diz Debert: "A tentativa está em precisar quais são os direitos e deveres dos pais, dos filhos e de cônjuges, companheiros ou vizinhos, judicializando áreas que não podem ser abandonadas à criatividade social" (Debert, 2006, p. 43).

Tal como nas instituições jurídicas e policiais estudadas por Debert (2006), em que há um deslocamento das preocupações: da luta contra a violência contra a mulher para a atenção à família, nas minhas pesquisas sobre as práticas de governo da infância e juventude evidencia-se que a defesa dos direitos das crianças e adolescentes está constantemente relacionada à proteção à família. Nesse campo de intervenções, no entanto, essa configuração não é, propriamente, uma novidade. As análises sobre a França realizadas por Jacques Donzelot (1980) já mostraram com eficiência a importância do "tribunal de menores" para a articulação e ascensão de uma série de novas autoridades e domínios de cercamento da família, mas como também esse novo campo de forças - o "complexo tutelar" - toma a família precisamente como o meio de ação de linhas diversas que, entrecruzadas, formam o "social", entendido

\footnotetext{
Ver também o relatório de pesquisa escrito por Daniel Simião et al. (2011) sobre tratamento judicial de casos de violência doméstica em juizados especiais do Distrito Federal. Em ambos os trabalhos, fica evidente, nas práticas cotidianas dos agentes jurídico-estatais, um deslocamento da noção de "proteção à mulher" para a "proteção à família". Chama a atenção, a título de exemplo desse processo, a recomendação constante de um juiz de um Juizado Especial do Distrito Federal, aos casais atendidos, para a criação de uma ética do "amor e respeito" entre marido e mulher, o marido contribuindo para o bem estar da relação a partir do amor à esposa e a mulher com respeito ao marido.
} 
como um setor particular em que se classificam problemas bastante diversos (Deleuze, 1980).

Em que pese as já realizadas observações sobre as diferenças entre os contextos brasileiro e francês, tais como a dificuldade de universalização do ensino no Brasil e a falta de políticas sedutoras de disciplinamento popular (Fonseca, 1995; Fonseca e Schuch, 2009), o que é interessante na pesquisa desse autor - e que considero fundamental para a análise ora empreendida - é a relação que faz entre o aparecimento de um domínio de formulação de problemas (o "social") e um conjunto de técnicas e autoridades de governo que se exercem através de um meio específico: a família.

Isto é, Donzelot (1980) interroga-se não apenas sobre a presença da família como foco de atenções de programas diversos de intervenção social, mas acerca do funcionamento da família na implantação e reconfiguração de determinadas tecnologias específicas de governo, o que incentiva interrogações mais pontuais e específicas sobre como a família funciona em práticas de intervenção social e na configuração de novos domínios de práticas. Para o objetivo aqui empreendido, esse modo de construção analítica é fundamental, uma vez que leva a relacionar os debates em torno da família e projetos de intervenção não apenas com dados, informações e questões colocadas para dentro desse campo de problematizações, mas também com um fora, isto é, com processos mais amplos de reconstrução democrática.

Especificamente para o campo de intervenções na infância e juventude, a reconstrução democrática implicou a configuração legal das crianças e adolescentes como "sujeitos de direitos", ensejando novas formas de governo. Essa configuração insere-se em uma preocupação com as artes de governo da infância e juventude no Brasil, a qual anteriormente (Schuch, 2009) especifiquei como podendo ser classificada em três diferentes matrizes de intervenção:

1. uma matriz higiênico-sanitarista destinada à produção de populações saudáveis e civilizadas, fundamentais para os processos de integração nacional e unificação da nação, no início do século 20 (1900-1950);

2. uma matriz modernista de desenvolvimento da nação (1950-1980), que teve como pano de fundo os projetos de fortificação do aparato estatal e o investimento na "modernização" do estado e da família e trabalhou fundamentalmente com a ambiguidade entre repressão e vigilância;

3. a atual matriz dos direitos (1980-...), que investe na participação da comunidade nas políticas de atendimento e reconfigura crianças e adolescentes como "sujeitos de direitos" e de proteção integral do estado, família e comunidade. 
É perceptível pelos estudos e pesquisas sobre esse campo de intervenções que a atenção à família foi constante nessas matrizes de intervenção; o que se pode discutir, entretanto, é sobre como tais preocupações fazem funcionar distintos modos de governo, interrogação que sustenta esse artigo. Em diálogo com as interrogações acima colocadas e, principalmente, com as inspirações das produções de Donzelot (1980) e Debert (2006), minha proposta é que, a partir dos estudos etnográficos das práticas em que os programas de intervenção ganham vida e com uma "lanterna empírica" (Hirschman, 1998, p. 88) bem aguçada, é possível perceber mais matizes nos modos de governo que empregam a família como um meio de ação.

Nesse sentido, proponho dois focos de discussão, baseando-se nas seguintes sugestões: de um lado, acredito que seja possível perceber, através da análise etnográfica de programas de intervenção social contemporâneos, um funcionamento da "família" enquanto instrumento para a promoção de novas racionalidades neoliberais que investem na responsabilização individual como mote das transformações sociais mais abrangentes. Aqui, dialogo com as linhas de pesquisa que trabalham com a expansão de uma racionalidade neoliberal nas práticas de governo contemporâneas, que investem na formação de competências e capacidades individuais para o autogoverno (Rose, 1999 e 2006). No entanto, trata-se de destacar, de outro lado, que tais elementos são também oportunidades abertas de reconfiguração e/ou revisão das próprias políticas, assim como de construção de novas práticas, relações e cenários culturais.

Isto porque é possível pensar que ao processo de "reprivatização de questões políticas" destacado por Debert (2006) se coaduna o processo que chamo de "politização da família". A família passa a ser não apenas uma instituição a ser preservada - a nossa "vaca sagrada", como destacou Fonseca (1995) -, e/ou um valor importante para certos grupos sociais em uma sociedade marcada por tensões entre princípios individualistas e holistas (Duarte, 1986), ou nem mesmo apenas um meio de ação em que novos domínios de formação de problemas são formados (Donzelot, 1980), mas um sujeito político fundamental para a mobilização de práticas de governo, mas também de luta por recursos, reputações e novas posições sociais.

Meu argumento fundamental é que a produtividade da questão sobre como a família funciona em políticas de intervenção social leva, inevitavelmente, a sua consideração como um sujeito político fundamental. E isso não apenas a coloca no centro da configuração de certas práticas de governo, mas também a configura como um agente e/ou recurso nas possibilidades de sua transformação e reinvenção. 
Este entendimento, relacionado com as interrogações sobre formas de governo neoliberais, impõe a compreensão de que o neoliberalismo não pode ser visto como uma ideologia unificada e imposta de cima para baixo, mas como um processo de expansão de certa racionalidade que é configurada significativamente em níveis e/ou composições locais, bastante heterogêneas (Collier, 2011; Ong e Collier, 2005; Tilton, 2010). Isso, no entanto, não é subestimar sua importância ou efeitos; ao contrário, é destacar o modo como compõe cenários dinâmicos que são, ao mesmo tempo, suas próprias condições de possibilidade e também elementos pelos quais novas associações, práticas e recursos culturais são produzidos.

Minha tentativa aqui será mostrar tais dinâmicas a partir da compreensão de dois programas de intervenção à infância e juventude em Porto Alegre, ambos estudados a partir do método etnográfico, em pesquisas finalizadas, respectivamente, em 2005 e 2006: a Escola de Pais, obrigatória para adolescentes em medida socioeducativa, e as Casas-Lar, destinadas a crianças e adolescentes com medida de proteção especial em decorrência de situação de vulnerabilidade social. Tais programas atendem a funções distintas, dentro das chamadas políticas de proteção integral à criança e ao adolescente propostas pelo ECA: políticas socioeducativas (para adolescentes autores de ato infracional) e políticas de proteção especial (para crianças e adolescentes em vulnerabilidade social).

\section{A Escola de Pais}

A "Escola de Pais" era propagada como um grupo de ajuda para pais ou responsáveis de adolescentes cumprindo medida socioeducativa. Sua existência compulsória para pais ou responsáveis por adolescentes em medida socioeducativa, é inusitada por si só, uma vez que se tratava da medida socioeducativa do filho; a medida judicial acabava se estendendo dessa forma também aos pais. No Juizado da Infância e da Juventude, a Escola de Pais era coordenada por psicólogas e apresentada por um casal de voluntários, Seu Omar e Dona Aparecida, de cerca de 60 anos, pertencentes às camadas médias porto-alegrenses. Nos encontros da "Escola de Pais", os familiares dos adolescentes eram motivados a compartilhar suas dúvidas acerca da educação dos filhos e pode-se dizer que a pedagogia da "Escola de Pais" não era centrada somente numa espécie de culpabilização familiar pela situação do filho, mas por diversos mecanismos retóricos que visavam suscitar uma reflexão interna, em cada pai, sobre o tipo de influência exercida sobre o filho.

O primeiro exercício proposto na "Escola de Pais", a qual acompanhei etnograficamente, foi significativo desta proposta. Na entrada do evento, recebíamos uma folha de ofício em branco. Posteriormente, Seu Omar ordenou 
que balançássemos as folhas intensivamente. O barulho das folhas de papel balançando no ar ecoou pela sala. No final do encontro, após explicar os objetivos e metodologia da "Escola de Pais", Seu Omar pediu para todos amassarem suas folhas de papel e, em seguida, desamassarem e novamente sacudi-las no ar. Seu Omar perguntou: "Vocês viram a diferença no barulho entre as folhas lisas e as amassadas?" E finalizou o encontro com uma significativa observação: “A folha amassada nunca é igual a uma lisa. Ela contém marcas. Que tipo de marcas vocês estão deixando nos seus filhos?"

No encontro seguinte, a temática foi: Que tipo de treinador você está sendo para seu filho? Entre as várias possibilidades apresentadas, me chamou a atenção a categoria "pai ausente". O "pai ausente" foi ilustrado com o desenho, em um cartaz, de uma mesa com mãe e filhos e com ponto de interrogação no lugar do pai. Seu Omar perguntou: "Onde estará o pai? No bar?" Uma senhora da plateia, mãe de adolescente, reagiu e sugeriu: “Trabalhando!” Seu Omar respondeu: "Pode ser, mas acho que esse pai aqui não está trabalhando..." Outra senhora disse, rindo: "Bebendo ou com a 'outra'?" A plateia riu, entusiasmada. $\mathrm{O}$ voluntário aproveitou a piada e deu um longo discurso moralizante sobre os males da bebida e a importância dos pais darem o exemplo para filho. Com relação às "outras", ou seja, as amantes dos maridos, Seu Omar começou a falar, através de um discurso psicologizante, que uma das funções do pai é exatamente retirar o vínculo exclusivo entre mãe e filho. "Vocês devem dar atenção para o homem também, porque senão eles vão reclamar", disse Seu Omar. "Reclamar não, eles arrumam outra", falou alto uma mulher, provocando a risada geral.

No fim da sessão, Seu Omar voltou à questão do "treinador", comparando a educação dos filhos com um treinamento de um time de futebol. Afirmou que, para um time perfeito, era necessário, sobretudo, "amor", "equilíbrio", "respeito" e "sinceridade". Em meu entender, todos esses elementos visavam introduzir reflexões sobre os deveres e obrigações paternas - a função do pai. Certa previsibilidade no seu comportamento e o diálogo na sua relação com os filhos foram enfatizados, expressando a preocupação com a autodisciplina dos pais e de sua atenção em relação aos filhos. Mas, sem dúvida, o gerenciamento afetivo na relação entre pais e filhos passava a ser definido, pela ética exposta na "Escola de Pais", como a fundamental obrigação paterna.

Essa mensagem explicitou-se de forma singular em um encontro que girou em torno do aprendizado e desenvolvimento da "inteligência emocional". A "inteligência emocional" ficou conhecida a partir da publicação do livro de autoajuda homônimo, escrito por Goleman (1995). O livro tornou-se um bestseller internacional nos anos 1990, ao pregar a necessidade de estar atento não 
somente aos princípios científicos da "inteligência racional/intelectual", mas à "inteligência emocional", ou seja, ao aprendizado do controle emotivo e à compreensão da influência do emocional para os diversos aspectos das interações humanas. Através da recuperação de alguns elementos dessa pedagogia específica, que valoriza a autoconsciência sobre a emoção e o sentimento, assim como seu controle, Seu Omar procurou destacar a importância da valorização das "emoções positivas", enumerando as três principais características de uma "inteligência emocional":

1. Ser sincero e entrar em contato com suas emoções. A ideia é de que conhecendo e reconhecendo suas emoções - através da autoobservação e autoconhecimento - as pessoas incrementam suas habilidades sociais e relações interpessoais, compreendendo melhor os outros e a si mesmos. Esse aprendizado envolve autodisciplina, mas conduz à administração dos próprios sentimentos;

2. Pedir permissão. Para entrar em contato com alguém, é necessário pedir permissão primeiro, ensinou Seu Omar. O voluntário afirmou que cada pessoa tem sua individualidade, que deve ser respeitada. Comentou que uma mãe não deve entrar no quarto dos filhos, antes de receber o seu consentimento. Ressalta-se que o respeito à individualidade do outro é, ao mesmo tempo, um aprendizado para a própria vida social, no sentido de limitar e controlar os impulsos violentos, que devem agora ser resolvidos através do diálogo e da troca empática das "emoções positivas";

3. Expressar sentimentos, mostrar amor, elogiar o próximo, noções que partem da ideia de um "reforço positivo" pelo carinho e diálogo, nas práticas educativas, ao invés do disciplinamento repressor da violência.

Enfim, com essas descrições o que desejo enfocar é que, pelas características dos encontros, pode-se compreender a "Escola de Pais" como um dispositivo que visa ensinar pais e responsáveis pelos adolescentes infratores a reconhecerem e gerenciarem suas emoções e suas manifestações apropriadas, desenvolvendo reflexões críticas sobre o papel dos pais na vida dos filhos. A pedagogia proposta é centrada em um modelo de família que privilegia os vínculos emocionais entre pais e filhos, próprio do sistema de valores das camadas médias e altas da população brasileira (Duarte, 1986; Fonseca, 1995).

A partir deste modelo pedagógico, criticam-se determinados valores e práticas, como o compartilhamento de autoridades na educação dos filhos, e salienta-se a necessidade de expressar sentimentos e emoções, como o "amor" e "sinceridade". O conselho de que se deve bater na porta do quarto, antes 
de entrar no quarto dos filhos, é revelador de outro aspecto dessa pedagogia específica: o investimento na preservação da "autonomia" e "privacidade" de cada indivíduo, valores que fazem sentido num modelo de família nuclear, característico das famílias burguesas, ou seja, de dinâmicas familiares que privilegiam o valor da igualdade e não da hierarquia.

Salienta-se que o que está sendo ensinado não é apenas como ser um "bom pai", mas como ser um novo sujeito. São esses mesmos valores que formam um "bom pai" - autodisciplina, autocontrole, igualdade, autonomia e privacidade - que constituem, a partir de uma racionalidade liberal, cidadãos responsáveis, os quais têm deveres e devem ser capazes de se autogerir (Ong, 2003; Rose, 1999 e 2006). É possível compreender a "Escola de Pais" nesse sentido, não apenas como um dispositivo de reorganização da família, mas de incentivo ao desenvolvimento de novas habilidades para a cidadania.

No entanto, esse processo é mais complexo, pois, ao mesmo tempo em que a "Escola de Pais" produz um diagnóstico sobre as famílias dos adolescentes infratores e uma correspondente pedagogia de reordenamento de suas relações, o riso constante e as brincadeiras dos pais, ao responderem às questões de Seu Omar, expõem outra faceta das relações sociais estabelecidas no Juizado da Infância e da Juventude, mais frequentemente visível em contextos "informais": a do riso provocado por uma sátira de suas próprias dinâmicas familiares. Tal sátira de suas práticas expressa uma reação irônica ao modelo pedagógico e as orientações apresentadas por Seu Omar na "Escola de Pais", evidenciando um questionamento importante acerca de sua possível absorção.

Esses elementos conduzem a uma observação importante: não há uma apropriação acrítica e passiva, por parte das famílias, da mensagem exposta na "Escola de Pais"; essa apropriação envolve confrontos de significado importantes. Obviamente, essa mensagem só poderia ser transmitida "entre linhas" no ambiente formal do Juizado da Infância e da Juventude e o riso, a sátira e a ironia pareciam ter essa função, no contexto da "Escola de Pais". Mas apareceu na pesquisa também a partir de minhas conversas com Vera, mãe da adolescente Michele, com 17 anos e, na época, executando uma medida socioeducativa em meio aberto.

Eu e Vera conversávamos muito sobre suas experiências de vida e sobre a criação dos filhos. Certamente, Vera considerava-se uma boa mãe. Mas sua forma de proteger os filhos estava longe daquela apresentada por Seu Omar. No intuito de proteger Michele, Vera já havia enviado a menina para viver com uma amiga, em Santa Catarina, para tentar afastá-la do contexto dos becos, do som e do namorado pelo qual a filha era apaixonada. O namorado, segundo Vera, costumava bater na jovem. Vera disse, ameaçadoramente: "Um dia desses 
ainda vou puxar cadeia por causa da Michele". Assegurou, corajosamente, que caso o namorado de Michele lhe batesse novamente, iria tentar matá-lo. Falou também que se a filha não se ajeitasse, iria entregá-la para internação na então Febem, já que, em sua opinião, já não tinha mais nada a fazer pela filha. Vera queria que Michele "se assustasse, visse o que é bom na Febem", como expressou.

O que desejo reter aqui, para além da própria valentia de Vera, é que Vera construiu uma narrativa sobre a proteção materna com os valores que, para ela, eram importantes: a proteção aos filhos, baseada num tipo de disciplinamento construído não apenas pela valorização do sentimento e do vínculo emocional entre pais e filhos, mas pela utilização de redes de ajuda mútua entre a própria família extensa e os seus amigos ou conhecidos e, também, a partir de uma espécie de "indigenização da medida socioeducativa", se quiséssemos usar a inspiração de Sahlins (1997). Isto porque Vera visualizava a possibilidade de uma espécie de coprodução disciplinar entre ela e uma instituição estatal de internação de adolescentes, caso Michele "não se ajudasse", categoria em que inscreve seu modo de fazer funcionar toda a retórica da autonomia e individualidade exposta na Escola de Pais.

\section{As Casas-Lar}

O segundo programa que gostaria de me deter diz respeito às políticas de proteção especial, destinadas a crianças e adolescentes abandonadas ou em situação de vulnerabilidade social por motivos diversos. Faz parte também da implementação legal da orientação de que toda a criança tem direito à convivência familiar e comunitária, proposta pelo ECA. Tal programa é conhecido, em nível municipal, como Casas-Lar. Estudei tal política, como disse anteriormente, juntamente com uma equipe de pesquisa do Núcleo de Antropologia e Cidadania (Naci, Ufrgs). Seu estudo interessa aos propósitos desse artigo porque no Rio Grande do Sul nota-se um investimento preferencial para o abrigamento de crianças e adolescentes em pequenas unidades de atendimento, com a possibilidade de receber até 15 pessoas e com um número reduzido de funcionários. Tais unidades são planejadas numa tentativa de desburocratizar o atendimento, retirar o estigma de um endereço institucional e aproximar-se de um modelo familiar no gerenciamento da socialização de crianças e adolescentes. Em nível municipal, tais equipamentos são terceirizados ou gerenciados e chamados de "CasasLar", enquanto no nível estadual tais unidades são chamadas de "Unidades Residenciais Transitórias" ou "Abrigos Residenciais", sendo geridas pelo próprio governo do estado. 
A pesquisa que realizei, junto com Claudia Fonseca, em 2005, visou entender a estrutura e configurações na rede de abrigamento em Porto Alegre, RS, tentando entender sua heterogeneidade e relacionalidade (Schuch e Fonseca, 2009). Uma das questões mais inquietantes que percebemos foi, justamente, que em paralelo a evidência desse modelo de família como modo de gestão da infância, havia uma crítica constante das unidades de abrigo, tomadas como as unidades "tradicionais" de atendimento, e uma tentativa de modificar tais estruturas, reduzindo seu tamanho e especialização funcional. Na verdade, a pesquisa apontou um verdadeiro sucateamento dos abrigos municipais, geridos diretamente pela prefeitura. A isso se adicionava, ainda, a existência de perfis diferenciais de crianças e adolescentes atendidos nos dois tipos de programas, tendo as casas-lar uma maior proporção de meninas mais jovens, brancas, com rompimento com suas famílias de origem e sem medidas socioeducativas, em comparação com os abrigos municipais onde um funcionário assinalou: "Aqui só vem o resto do resto", salientando o recebimento de proporcionalmente maior número de negros e pardos, meninos, com histórico de uso de drogas, medidas socioeducativas e relacionamentos intercorrentes com suas famílias de origem. ${ }^{2}$

Para além de simplesmente apontar uma ineficácia da gestão municipal no atendimento de crianças e adolescentes abrigadas, acho importante relacionar tal situação com escolhas políticas vinculadas a uma filosofia de governo particular que investiu nas políticas de formulação de parcerias e corresponsabilização comunitária na execução das políticas a partir de processos de terceirização de serviços, em paralelo com políticas de sucateamento de equipamentos próprios. Tal sucateamento institucional tornava as entidades de abrigo mais estigmatizáveis, justificando seu remodelamento e a política de racionalização do Estado frente ao abrigamento de crianças e adolescentes realizada a partir da celebração do modelo de nuclearização do atendimento terceirizado. O modelo da família nuclear funcionava, nesse caso, como um instrumento de racionalização das políticas municipais.

Outra faceta desse processo pode ser vista quando consideramos os motivos de ingresso das crianças e adolescentes na rede municipal de acolhimento. Os resultados da pesquisa mostraram uma espantosa responsabilização da família de origem. As três principais categorias mais citadas foram: "negligência", com 25,3\%; "abandono", com 18,2\% e "violência doméstica", com 15,1\%, o que conjuntamente resulta em cerca de $60 \%$ dos casos. O percentual da categoria "carência de recursos materiais da família/responsável (pobreza)" só apareceu

\footnotetext{
2 Para uma análise detalhada dos dados quantitativos, ver Schuch e Fonseca (2009).
} 
em quinto lugar, com um percentual baixo - 8,3\% -, mesmo em relação à média nacional sobre o assunto, encontrada na pesquisa realizada pelo Instituto de Pesquisa Econômica Aplicada (Ipea) em 2005, que foi de 24,1\% (Ipea, 2005).

Esse baixo índice poderia estar associado a uma rede de assistência social efetiva que impedisse o ingresso de crianças e adolescentes por carência de recursos nas unidades de abrigo. Contudo, o pequeno percentual de apenas $21 \%$ das crianças e adolescentes nos equipamentos para abrigamento terem famílias vinculadas a algum programa de assistência social parece problematizar essa hipótese. Vale a pena, entretanto, investir numa hipótese de que esteja havendo um maior conhecimento da lei, o ECA, que orienta que nenhuma criança ou adolescente seja abrigada apenas por motivos socioeconômicos. Associa-se a isso uma visão sobre gestão da infância e juventude que privilegia a família como causa e solução de todos os problemas do indivíduo e ela própria formadora de indivíduos saudáveis, responsáveis e autônomos. Há uma evidente individualização das questões tratadas, o que impede a percepção de contextos mais amplos nos quais a própria gestão da criança se faz e que importam para compreender a própria distribuição de recursos sociais básicos como educação, trabalho e renda.

Tal individualização pode ser pensada, tal como fizeram Fonseca e Cardarello (1999), como tendo relação com a própria reconfiguração dos modos de gestão da infância e juventude, em que a família pobre e não uma questão estrutural é a culpada e responsabilizada pela situação dos filhos:

A passagem do "problema socioeconômico" para "negligência" revela uma mudança de enfoque na visão da infância pobre e da sua família no Brasil. Se em 1985 considerava-se que motivos como "mendicância", "maus tratos", "desintegração familiar" e "doenças do menor" eram decorrência direta de "problemas socioeconômicos", hoje, mais do que nunca, a família pobre, e não uma questão estrutural, é culpada pela situação em que se encontram seus filhos (Fonseca e Cardarello, 1999, p. 107).

Isto é, ao se enfatizar a família como culpada pelo abrigamento dos filhos há um correlato apagamento de outras questões mais estruturais que certamente contribuem na necessidade de abrigamento de crianças e adolescentes. Não fica difícil, então, justificar as ênfases na adoção plena nas políticas brasileiras ou mesmo, no caso aqui mostrado, a existência de uma celebração de um modelo de atendimento ideal - as Casas Lar - que trabalha a partir da noção de substituição familiar - haja vista que os percentuais mais altos de crianças 
e adolescentes destituídas do poder familiar encontravam-se exatamente nas "casas lar", em comparação com os grandes abrigos. O "tipo ideal" do atendimento trabalhava a partir de um "modelo de ruptura", em oposição aos "modelos de continuidade" das relações de parentesco entre a família substituta e a família de origem. ${ }^{3}$

No entanto, mais uma vez, a atenção etnográfica revela práticas inesperadas: sendo as mães sociais muitas vezes mulheres de classes trabalhadoras ou de camadas médias baixas, moradoras de contextos sociais similares àqueles das próprias crianças colocadas nos equipamentos, em que pese a ênfase institucional nuclear do modelo das Casas-Lar, tais mulheres acabavam constituindo, nas suas práticas cotidianas de criação de crianças e adolescentes, relações mais abrangentes entre os habitantes de suas casas e suas próprias famílias extensas ou redes mais amplas de relações, tencionando o próprio modelo familiar nuclear proposto. Em ao menos um caso por mim estudado, uma "mãe social" moradora da periferia de Porto Alegre acabou descobrindo a mãe biológica de algumas crianças de sua casa e passou a organizar visitas regulares entre filhos e mãe, tudo isso extraoficialmente.

\section{Considerações finais}

O estudo desses dois programas de intervenção, que se constroem a partir da reconfiguração de práticas de proteção à infância e juventude depois da implementação do ECA, mostra que a partir dessa nova legislação há dois movimentos inter-relacionados: não apenas as crianças têm o direito de serem educadas no seio de uma família, mas as famílias são cada vez mais responsabilizadas pela violência social e pela gestão das crianças e adolescentes. A implantação de modelos de atendimento inspirados na estrutura de "família", como as "Casas-Lar" aqui descritas, nos dá mostras da centralidade que esse ente assume nas políticas de atendimento. Os percentuais de motivos de ingresso nos abrigos em Porto Alegre associados à ação maléfica paterna são outro exemplo, assim como a própria efetivação da "Escola de Pais" como obrigatória para o cumprimento da medida socioeducativa de adolescentes considerados infratores. Essa situação ecoa a dinâmica do que Guita Debert (2006), ao estudar as delegacias de defesa da mulher, chamou de "reprivatização das questões políticas".

A autora também refere uma possível associação entre o momento atual e o período próximo da década de 1930, onde família e judiciário foram rochas

\footnotetext{
3 Sobre a noção de modelos de ruptura e modelos de continuidade, nas políticas de proteção à infância no Brasil, ver Fonseca (2006).
} 
fundamentais na construção de uma nova nação e um novo sentido cívico. Sem dúvida tal associação está presente nos dois momentos da história brasileira; não obstante, parece-me que seus propósitos e efeitos parecem ser dessemelhantes. Isto porque a preeminência da família e do judiciário foi importante, por volta da década de 1930, para expandir os controles estatais em domínios até então inexplorados. Hoje, tal ênfase parece ter um sentido oposto, na medida em que está "funcionando" para a racionalização das intervenções sociais estatais nesse domínio. No primeiro caso temos uma articulação para a constituição da infância como um domínio de intervenções "sociais" e a legitimação de novas autoridades para sua gestão, processo semelhante ao descrito por Donzelot (1980), ao refletir sobre a formação do "complexo tutelar" para o caso da França. Atualmente, talvez estejamos apostando numa racionalidade política de "reprivatização" desse domínio. No início do século passado era preciso criar uma "nação"; hoje, com sua consolidação, a tarefa que se impõe talvez seja outra, a formação de "sujeitos de direitos", cidadãos ativos e aptos para a sua autogestão.

A família, nesse sentido, não só aparece como um domínio de formação da matriz para o indivíduo adulto (Foucault, 1977 e 1979), mas parece estar inserida em políticas mais amplas de reconstrução democrática que priorizam a descentralização das políticas, corresponsabilização de indivíduos e comunidades na sua execução e a construção da autonomia e protagonismo dos sujeitos, com vistas a sua transformação em "sujeitos de direitos". Importa considerar, portanto, que ao processo de "reprivatização das questões políticas", descrito por Debert (2006) corresponde à "politização da família". Como tentei mostrar nessa apresentação, a atenção para esses processos, embora extremamente importante, não pode ofuscar um movimento paralelo: a compreensão da complexidade de dinâmicas, valores, agentes e interesses que coproduzem tais práticas de mudança nos modos de governo de indivíduos e populações e os expandem em outras direções. A família parece funcionar, então, como um sujeito político fundamental para a mobilização de práticas de governo, mas também de luta por recursos, reputações e novas posições sociais.

\section{Referências}

COLLIER, Stephen J. Post-Soviet social: neoliberalism, social modernity, biopolitics. Princeton: Princeton University Press, 2011. p. 1-30 e 202-244.

DEBERT, Guita Grin. Conflitos éticos nas Delegacias de Defesa à Mulher. In: DEBERT, Guita Grin; GREGORI, Maria Filomena; PISCITELLI, Adriana Gracia (Orgs.). Gênero e distribuição da Justiça: as delegacias de defesa da mulher e a construção das diferenças. Campinas: Pagu/Unicamp, 2006. 
DELEUZE, Gilles. Prefácio: a ascensão do social. In: DONZELOT, Jacques. A polícia das famílias. Rio de Janeiro: Graal, 1980. p. 5-11.

DONZELOT, Jacques. A Polícia das Famílias. Rio de Janeiro: Graal, 1980.

DUARTE, Luiz Fernando Dias. Da vida nervosa (nas classes trabalhadoras urbanas). Rio de Janeiro: Jorge Zahar Editor, 1986.

. Ethos privado e modernidade: o desafio das religiões entre indivíduo, família e congregação. In: DUARTE, Luiz Fernando Dias et al. (Orgs.). Familia e religião. Rio de Janeiro: Contra Capa Livraria, 2006. p. 51-87.

GOLEMAN, Daniel. Inteligência emocional: a teoria revolucionária que redefine o que é ser inteligente. Rio de Janeiro: Objetiva, 1995.

FONSECA, Claudia. Caminhos da adoção. São Paulo: Cortez, 1995.

. Da circulação de crianças à adoção internacional: questões de pertencimento e posse. Cadernos Pagu, Campinas, v. 26, p.11-43, jan.-jun. 2006.

FONSECA, Claudia; CARDARELLO, Andrea. Direitos dos mais e dos menos humanos. Horizontes Antropológicos, Porto Alegre, v. 5, n. 10, p. 83-121 maio 1999.

FONSECA, Claudia; SCHUCH, P. (Orgs.). Políticas de proteção à infância: um olhar antropológico. Porto Alegre: Editora da Ufrgs, 2009.

FOUCAULT, Michel. História da sexualidade 1: a vontade do saber. Rio de Janeiro: Graal, 1977.

. Microfísica do poder. Rio de Janeiro: Graal, 1979.

HIRSCHAM, Albert. Crossing boundaries: selected writings. New York: Zone Books, 1998.

IPEA (Instituto de Pesquisa Econômica Aplicada). $O$ direito à convivência familiar e comunitária: os abrigos para crianças e adolescentes no Brasil. Brasília: Ipea, dezembro de 2005.

ONG, Aihwa. Buda is hiding: refuges, citizenship and the New America. Berkeley: University of California Press, 2003. p. 1-24; 67-191.

ONG, Aihwa; COLLIER, Stephen (Orgs.). Global assemblages technology, politics and ethics as anthropological problems. Oxford: Blackwell Publishing, 2005.

RIBEIRO, Fernanda Bittencourt. A inserção do Conselho Tutelar na construção do problema social da infância e adolescência. Dissertação de Mestrado apresentada ao Programa de Pós-Graduação em Antropologia Social da Universidade Federal do Rio Grande do Sul. Porto Alegre: Ufrgs, 1996 (mimeo).

RIBEIRO, Ivete; RIBEIRO, Ana Clara T. (Orgs.). Família em processos contemporâneos: inovações culturais na sociedade brasileira. São Paulo: Loyola, 1995.

ROSE, Nikolas. Powers offreedom: reframing political thought. Cambridge: Cambridge University Press, 1999.

Governing "advanced" liberal democracies. In: SHARMA, Aradhana; GUPTA, Akhil (Orgs.). The anthropology of the state: a reader. Oxford: Blackwell, 2006. p. 144-162. 
SAHLINS, Marshall. O "pessimismo sentimental" e a experiência etnográfica: porque a cultura não é um "objeto" em via de extinção (Parte 1). Mana, Rio de Janeiro, v. 3, n. 1, p. 103-150, out. 1997.

SCHUCH, Patrice. Práticas de justiça: antropologia dos modos de governo da infância e juventude no contexto pós-ECA. Porto Alegre: Editora da Ufrgs, 2009.

SCHUCH, Patrice; FONSECA, Claudia. Diversidade, desigualdade: os "direitos da criança" na prática: o sistema de abrigamento de crianças e adolescentes em Porto Alegre. In: FONSECA, Claudia; SCHUCH, Patrice. Políticas de proteção à infância: um olhar antropológico. Porto Alegre: Editora da Ufrgs, 2009. p. 115-144.

SCHUCH, Patrice. Justice, culture and subjectivity. Vibrant, Brasília, v. 9, n. 2 , p. 34-69, July-Dec. 2012.

SIMIÃO, Daniel Schroeter. et al. Uma análise do tratamento judicial de casos de violência doméstica em perspectiva comparada, no Distrito Federal. Relatório final de pesquisa. Brasília, Programa de Pós-Graduação em Antropologia Social da UnB, 2011. (mimeo)

TILTON, Jennifer. Dangerous or endangered? Race and the politics of youth in urban America. New York: New York University Press, 2010.

VIANNA, Adriana. Limites da menoridade: tutela, família e autoridade em julgamento. Tese de doutorado defendida no Museu Nacional, UFRJ. Rio de Janeiro, 2002. (mimeo)

VIANNA, Adriana de R. Direitos, moralidades e desigualdades: considerações a partir de processos de guarda de crianças. In: KANT DE LIMA, Roberto (Org.). Antropologia e direitos humanos 3. Niterói: Editora da UFF, 2005. p. 13-67.

\section{Autora correspondente:}

Patrice Schuch

Rua Felipe Camarão, 175, apto. 403

90035-141 Porto Alegre, RS, Brasil

Recebido em: 5 jul. 2013

Aprovado em: 9 out. 2013 